\title{
A trajetória do monsenhor Luigi Pescarmona e as lutas pela reforma agrária na Diocese de Guarabira/PB
}

\section{The trajectory of monsignor Luigi Pescarmona and the movement for the agrarian reform in the Diocese of Guarabira/PB}

Resumo: No artigo, procuramos responder a questão de como seu deu a trajetória religiosa-política do padre italiano Luigi Pescarmona entre duas grandes transições no campo religioso católico: o Concílio do Vaticano e a crise da Teologia da Libertação, a partir da década de 1980. Entre a década de 1960 e 1990, analisamos como ocorreu uma experiência religiosa-política do padre Pescarmona, por meio de um habitus partisão, ligado à Teologia da Libertação, cuja relação se deu com a reforma agrária no estado da Paraíba. Os aportes de Pierre Bourdieu fomentaram a percepção sobre a dinâmica do campo político, as disputas simbólicas, os conflitos entre classes e de representações. Quanto à contribuição micro histórica, recorremos ao uso das escalas, que nos permitiu perscrutar as fontes disponíveis. Utilizamos fontes orais, bibliográficas, primárias, artigos de jornais e documentos oriundos de arquivos judiciais.

Palavras-chave: Biografia, trajetória, Teologia da Libertação

\begin{abstract}
We search to explain, through different sources, the question on how the religious political trajectory of the Italian priest called Luigi Pescarmona occurred. Luigi Pescarmona followed his calling under the influence of Italian priests who were opposed to the fascist regime, besides he belonged to a catholic family with socialist tendencies. His religious career was developed during two big transitions in the catholic religious field: The Vatican Council and the Liberation Theology crisis in the 1980s. We analyze his political religious practices during the period of 1960 to the 1990s through the partisan habitus, linked to the Liberation Theology, related to agrarian reform especially in the state of Paraíba, northeast of Brazil. Pierre Bourdieu's theoretical approach fomented our perception about the dynamics in the political field, the symbolic disputes, classes and representation conflicts in different societal levels. Regarding the micro historical contributions, we used the
\end{abstract}

\footnotetext{
${ }^{*}$ Professor de História do Brasil na UEPB. Doutor em Ciências Sociais/UFCG.
} 


\section{Revista Brasileira de História \& Ciências Sociais - RBHCS}

Vol. $8 \mathrm{~N}^{\circ}$ 16, Julho - Dezembro de 2016

methodological approach of scales which allowed us a fair analysis of the available sources. As sources, we used oral narratives, bibliographical documents, primary sources, newspaper articles, and court law archives.

Keywords: Biography, Trajectory, Liberation Theology

A relação entre religiosos católicos e a política na década de 1960 (e nas posteriores) assumiu um aspecto pautado por uma cisão significativa: a emergência de membros da hierocracia ligados aos grupos da esquerda laica. Essa condição tornou frequente um corpo de acusações dos grupos políticos tradicionais sobre membros do alto e do baixo clero como agentes políticos insufladores dos trabalhadores como verdadeiros defensores do "comunismo". Esse marco temporal é significativo, porque quase sempre os membros do clero católico possuíram relações cordiais com o Estado brasileiro ou com grupos de proprietários urbanos e rurais, auxiliando na contenção de conflitos sociais. No Nordeste do Brasil, o chamado Frei Damião de Bozzano foi um pregador vigoroso contra as influências socialistas e comunistas, reiterando nas suas predicas o cuidado necessário aos cristãos com este tipo de influência política. Dentro das balizas demarcadoras dos vínculos entre religião e política, realizamos uma pesquisa que resultou na nossa tese, na qual investigamos a participação de um padre italiano com as demandas por reforma agrária e direitos sociais, mormente, entre camponeses na área compreendida pela administração de Dom Marcelo Carvalheira (então bispo auxiliar da Arquidiocese da Paraíba), cuja importância eclesiástica resultou no surgimento da Diocese de Guarabira $^{1}$. A nova diocese localizada no município de Guarabira, agreste paraibano, contava com um bispo ligado a outros religiosos de notória militância na Teologia da Libertação como Frei Betto, Dom Helder Câmara e Dom José Maria Pires. Em 9 de novembro de 1981 foi criada a Diocese de Guarabira, que já contava com um grupo de religiosos e leigos dedicados a uma interlocução com grupos de trabalhadores rurais e urbanos em situações de litígio com os patrões.

\footnotetext{
${ }^{1}$ Conforme o $1^{\mathrm{o}}$. Livro de Tombo da Diocese de Guarabira (1981-1997), a Diocese de questão era constituída no momento da sua implantação, em 1981, de 23 municípios: Guarabira, Araçagi, Pilõezinhos, Araruna, Cacimba de Dentro, Tacima, Solânea, Bananeiras, Dona Inês, Serraria, Borborema, Pilões, Arara, Alagoinha, Mulungu, Cuitegi, Pirpirituba, Belém, Mari, Serra da Raiz, Caiçara, Duas Estradas e Lagoa de Dentro.
} 


\section{Revista Brasileira de História \& Ciências Sociais - RBHCS}

Vol. $8 \mathrm{~N}^{\circ}$ 16, Julho - Dezembro de 2016

Na década de 1960, fase de grande agitação política com destaque às mobilizações de camponeses e operários, grupos de religiosos estrangeiros, principalmente europeus, estabeleceram-se nas mais variadas regiões do Brasil. Muitos desses padres e freiras chegaram aos trópicos imbuídos de uma ação clerical orientada pelos princípios do Concílio do Vaticano II (1962-1965), caracterizado pelo ecumenismo e pela descentralização, e que se chocava com os padrões do catolicismo tradicional, afeito ao centralismo, especialmente, por causa das tensões originadas do liberalismo, do socialismo, do comunismo e das igrejas protestantes.

Realizamos um trabalho de história oral de vida, através de entrevistas semiestruturadas, com um padre italiano chamado Luigi Alberto Pescarmona, cuja primeira área de atuação no Brasil foi Teófilo Otoni (Minas Gerais), onde acompanhou, na década de 1960, as populações de trabalhadores das minas e camponeses. Muitos desses trabalhadores realizaram migrações em decorrência da crise do setor minerador. Para isso, elegeram como destino a Região Norte ou áreas metropolitanas, devido à violência no campo.

Depois dessa fase, o Padre Pescarmona transferiu-se para o estado da Paraíba, no fim da década de 1970, e radicou-se na área sob a responsabilidade do Bispo auxiliar, D. Marcelo Carvalheira. Quanto ao caráter mais específico deste trabalho, algumas questões nortearam nossa abordagem: como se deu a militância política de um padre estrangeiro no agreste paraibano nas décadas de 1980 e 1990? Quais os limites dessa prática nas fronteiras dos campos político e religioso? Como um conflito no campo religioso também foi instaurado? Assim, objetivamos analisar como foi feita a prática de um agente da Teologia da Libertação (TL) em uma área, até então, pautada pelo catolicismo de bases anteriores ao Vaticano II.

Nosso primeiro contato com o Padre Luigi Pescarmona foi no ano de 2004, quando fizemos algumas incursões na Comissão Pastoral da Terra (CPT), com o objetivo de visualizar a dinâmica da atuação da Igreja na área da Diocese de Guarabira, na Paraíba. Encontramo-nos no momento de uma refeição e tomamos uns goles de café juntos, enquanto conversamos animadamente sobre as razões de minha presença na CPT, fazendo leituras de recortes de jornais e de relatórios. O padre, então, abriu um flanco a partir de narrativas sobre a questão agrária na Paraíba e o seu envolvimento com as áreas de conflito. Elaboramos um projeto e o procuramos para outra conversação, em que fizemos o convite para realizar a série de entrevistas, 


\section{Revista Brasileira de História \& Ciências Sociais - RBHCS}

Vol. $8 \mathrm{~N}^{\circ}$ 16, Julho - Dezembro de 2016

que ocorreram na sala de reunião da CPT (quando os serviços e as pastorais se concentravam em um prédio vizinho ao Palácio Episcopal, nas proximidades da Catedral de Guarabira) e, eventualmente, na residência do padre ou na Comunidade Talita. O trabalho de entrevistas prolongou-se por cerca de um ano e, no fim, submetemos as transcrições para eventuais correções, que demandaram novas entrevistas, visando esclarecimentos. Isso prolongou mais um pouco o trabalho e, por fim, obtivemos um documento firmado em cartório, autorizando a publicação de trechos ou da totalidade dos registros.

A opção pelo estudo da trajetória associou-se à metodologia da história oral com o cruzamento de outras fontes em nossa pesquisa: jornais, relatórios, processos-crimes, cartas e trabalhos acadêmicos. Quanto à história oral, buscamos em Saltalamacchia dois fundamentos metodológicos: o primeiro, a questão do "sentido", e o segundo, o caráter da coinvestigação. O termo "sentido" é definido como

el lugar que ocupan los hechos en la "estructura de relevancias" que organizan la percepción activa del sujeto. Esa estructura de relevancias está fundada (...) en los valores, saberes y certezas que, según se supone, el interpelado comparte, en algunos casos, con casi todos sus contemporáneos y en otros con sólo algunos de ellos (...) La historia de vida permite preguntar al entrevistado sobre ese sentido particular que para él tuvieron los actos en el momento de ocurrir (SALTALAMACCHIA, 1992, p. 81).

Essa é uma forma de estabelecer possibilidades de análise dos conteúdos da memória. Já o caráter da coprodução nos sugere uma experiência de pesquisa em que se visualiza o contexto a partir de um caráter dinâmico, fruto das relações do indivíduo com diversos campos sociais com os quais se relaciona (SALTALAMACCHIA, Op. cit., p. 85).

A questão da coprodução permite um conjunto de análises e a aplicação dos critérios éticos exigidos pela história oral, pois nem todas as memórias, mesmo quando narradas, são publicadas, e isso exige o estabelecimento de um acordo entre entrevistador e entrevistado. A partir dessas possibilidades metodológicas, realizamos pesquisas em outras fontes, visando construir um conjunto de referências para perscrutar a participação do Padre Luigi Pescarmona na CPT e sua relação com os conflitos no campo. Alguns eixos, inicialmente, fizeram gravitar nossas entrevistas: a vida na Itália na fase da II Guerra Mundial (II GM) e o início da vida como padre no Brasil nos anos 1960. As duas temporalidades nos traziam uma série de imagens a 


\section{Revista Brasileira de História \& Ciências Sociais - RBHCS}

Vol. $8 \mathrm{~N}^{\circ}$ 16, Julho - Dezembro de 2016

partir das narrativas do padre, cuja família tinha vínculo com a resistência italiana ao fascismo, através dos grupos de guerrilheiros partigiani (constituídos por uma variedade de tendências políticas, como católicos, liberais, socialistas e comunistas) atuantes em várias frentes. O segundo eixo nos fez dialogar longamente sobre sua formação de padre durante o Concílio do Vaticano II e sua preparação para atuar no Brasil. Posteriormente, detivemo-nos em sua militância na CPT e junto aos camponeses da Paraíba.

As narrativas sobre a infância nos arrabaldes da cidade de Alba (Cuneo), região do Piemonte, no curso da II GM, com o desenvolvimento de uma série de conflitos entre os partigiani e as tropas nazifascistas, deram-nos condições para perceber a formação de um habitus ${ }^{2}$ relacionado às questões sociais (PAIVA NETO, 2013). A Diocese de Alba teve uma especificidade no contexto político italiano: a presença de D. Luigi Grassi, cuja proximidade com os guerrilheiros do Norte da Itália o fez ficar conhecido como o "bispo partisão" (GRASSI, 1994). Ademais, a condição de camponês trabalhador3, em Canale D'Alba4 de Cesare Pescarmona (pai de Luigi Pescarmona), de opção política socialista e membro da resistência (na condição de apoiador), possibilitou a convivência com processos sociais relacionados às experiências de classe do campesinato e do operariado piemontês, bem como à formação de uma memória sobre lutas sociais. O contato com um contexto social marcado pela exploração figura como um estímulo ao trabalho de memória sobre a experiência paterna (e dos demais trabalhadores) e de suas modalidades organizativas. Os camponeses-trabalhadores, os "braccianti" e demais camponeses

\footnotetext{
2 A noção de habitus é a de um "sistema de disposições duráveis, estruturas estruturadas predispostas a funcionar como estruturas estruturantes, isto é, como princípio gerador $e$ estruturador das práticas e das representações que podem ser objetivamente 'regulamentada' $e$ 'reguladas' sem ser o produto de obediência a regras, objetivamente adaptadas a seu fim sem supor a intenção consciente dos fins e o domínio expresso das operações necessárias para atingi-los $e$ coletivamente orquestradas, sem ser o produto ação organizadora de um regente" Bourdieu (1994, p. 61). Aqui, encontramos uma tensão entre o indivíduo e a estrutura social, pois o habitus é produto, mas é igualmente produtor como um princípio gerador de práticas e representações.

3 O camponês trabalhador tem as seguintes características: 1) Sua condição é de uma adaptação permanente e de longa duração, que tem emergido em resposta às mudanças estruturais dentro das sociedades industriais. Essa categoria é histórica, tem existido desde o Século XVIII, na Itália, e se desenvolvido desde a II GM; 2). É um processo que se relaciona com a dinâmica familiar e as fases da vida, tais como casamento, reprodução, educação de crianças e aposentadoria; 3) Os camponesestrabalhadores persistem ao longo da gerações. (Cf. HOLMES, p. 734-748 apud MENEZES, 2002, p. 46.). Essa classificação define um proletário de uma aldeia, cujos rendimentos são obtidos fora da sua comunidade. O camponês-trabalhador realiza trabalhos não agrícolas na cidade e ofícios agrícolas em sua aldeia por longas horas. O cultivo de uvas e a atividade vinícola eram conhecidos pelos Pescarmona, mas Cesare Pescarmona também trabalhava numa empresa de farináceos.

4 Alba localiza-se próximo a Turim, centro de agitações operárias na década de 1920.
} 


\section{Revista Brasileira de História \& Ciências Sociais - RBHCS}

Vol. $8 \mathrm{~N}^{\circ}$ 16, Julho - Dezembro de 2016

proletarizados fizeram parte de um contexto de conflitualidade, que aflorou na memória do religioso por sua relação familiar, a partir dos enleios com a participação política. Esse fato pode estar associado a algumas questões da experiência e das vicissitudes apontadas na biografia por Giovanni Levi do padre piemontês Giovan Battista Chiesa, um exorcista do Século XVIII. De acordo com Jacques Revel,

todas as estratégias pessoais e familiares talvez tendam a parecer atenuadas em meio a um resultado comum de relativo equilíbrio. Todavia, a participação de cada um na história geral e na formação e modificação das estruturas essenciais na realidade social não pode ser avaliada somente com base nos resultados perceptíveis: durante a vida de cada um aparecem, ciclicamente, problemas, incertezas, escolhas, enfim, uma política da vida cotidiana cujo centro é a utilização estratégica das normas sociais. A intenção anuncia-se claramente: a abordagem micro-histórica deve permitir o enriquecimento da análise social, torná-la mais complexa, pois leva em conta aspectos diferentes, inesperados, multiplicados pela experiência coletiva (REVEL, 2000, p.18).

No caso do exorcista piemontês, Giovan Chiesa, as questões que lhe tocavam mais diretamente diziam respeito às estratégias do religioso na Igreja e na aldeia de Santena, em uma região afetada por conflitos entre camponeses, entre as perspectivas em torno do sagrado e da política referente às tensões das comunidades diante da centralização estatal (GRIBAUDI, 1998, p. 129).

Em relação ao padre Luigi Pescarmona, essas interações passavam também pelas questões de ordem política, pois atualizavam alguns aspectos experienciados pelo próprio religioso na fase em que viveu na casa paterna. Em nossa pesquisa, chamamos esse habitus de "partisão" por sua relação com uma experiência política e de classe. Realizando um estudo sobre memórias, Connerton (1993, p. 47-48) visualizou como a memória pode motivar ações em indivíduos, no sentido de se tornarem herdeiros dos acontecimentos marcantes de sua classe. $\mathrm{O}$ ato de lembrar e de expressar para outrem uma memória (através da palavra ou dos atos políticos) expressa a constituição de um passado em que se gestou um habitus de classe passível também de ressignificação na própria performance de um religioso empenhado em uma pastoral relacionada à reforma agrária. Assim, o habitus é estruturado e estruturante, como um ato de rememorar, e conjuga tempos verbais pretéritos e do presente. Isso explica que, embora um indivíduo tenha como profissão a vida religiosa, podemos perceber elementos relacionados a um habitus de classe por 


\section{Revista Brasileira de História \& Ciências Sociais - RBHCS}

Vol. $8 \mathrm{~N}^{\circ}$ 16, Julho - Dezembro de 2016

meio da própria socialização primária relacionada à experiência familiar. Esse habitus faz vibrar no tempo presente vozes e ecos do passado.

É necessário levarmos em conta a importância da oposição da população piemontesa ao fascismo. Essa área, devido à sua industrialização, tinha uma forte tradição comunista entre os trabalhadores urbanos e nas áreas rurais ocorreram conflitos sociais intensos, que foram duramente reprimidos pelos fascistas entre 1918 e 1922 (SASSON, 2009, p.24). O norte italiano tinha o seu cotidiano marcado pelo movimento operário com uma organização sindical e partidária fortemente vascularizada, responsável pela eleição parlamentar do próprio Antonio Gramsci (MAESTRI, CANDREVA, 2001), na fase anterior ao fascismo5. Porém, a partir de 1944, a presença das tropas aliadas no sul da Itália desestabilizou o governo fascista. Assim, houve ações de tropas regulares e a adesão de muitos civis aos grupos da resistência que, com ataques em diversas áreas, capilarizaram as ações bélicas sufocando os nazifascistas. Avaliando os movimentos de resistência europeus, Hobsbawm caracterizou uma diversidade e níveis de participação:

Duas coisas se deve dizer (...). Primeiro, sua importância militar (com a possível exceção da Rússia) foi insignificante antes de a Itália retirar-se da guerra em 1943, e não decisiva em parte alguma, com exceção talvez de partes dos Bálcãs. Deve-se repetir que seu significado foi político e moral. Assim, a vida pública italiana foi transformada, após mais de vinte anos e um fascismo que desfrutara de considerável apoio até mesmo entre os intelectuais, pela mobilização impressionante e generalizada da Resistência em 1943-45, incluindo um movimento partisan armado no Centro e Norte da Itália de por volta de 100 mil combatentes, com 45 mil mortos (...) Enquanto os italianos podiam deixar a memória de Mussolini para trás com a consciência limpa, os alemães, que tinham apoiado o seu governo até o fim, não podiam colocar distância entre eles próprios e a era nazista de 1939-45 (...) A segunda observação sobre a Resistência é que (...) com a notável exceção da Polônia, sua política pendia para a esquerda. Em cada país os fascistas, os radicais de direita, os conservadores, ricos locais e outros cujo principal terror era a revolução social, tendiam a simpatizar, ou pelo menos não se opor aos alemães (...). O mesmo, não se deve esquecer, fizeram os elementos profunda e intransigentemente anticomunistas na Igreja Católica e seus exércitos de religiosos convencionais, embora a política da Igreja fosse demasiado complexa para ser classificada simplesmente como 'colaboracionista' em qualquer parte (HOBSBAWN, 1995, p. 165-166).

Essas considerações nos aguçam a perceber a existência de brechas na sociedade italiana que, mesmo sob as violências do regime fascista, pôde dar uma demonstração de resistência política a partir de grupos de civis em armas,

5 Sobre o fascismo como regime (1926-1943), sugerimos a leitura de: LUPO, Salvatore. Il fascismo: la politica in um regime totalitario. Roma: Donzelli Editore, 2005. 


\section{Revista Brasileira de História \& Ciências Sociais - RBHCS}

Vol. $8 \mathrm{~N}^{\circ}$ 16, Julho - Dezembro de 2016

demonstrando como as ações dos partigiani junto com os aliados foram eficazes para a derrota de Mussolini em 1945.

Com o fim da guerra, o esforço para reconstruir a sociedade italiana tomou corpo, por meio de um processo de pacificação que envolveu vários agentes políticos: a Democracia Cristã, os socialistas e os comunistas. Sobre a reestruturação italiana depois da II GM, obtivemos algumas referências que demonstram o nível de participação na política: os traumas em relação ao fascismo e os temores diante de outro governo que pudesse flertar com uma feição autoritária, no caso específico dos comunistas simpáticos a Iosif Stalin. Segundo o Padre Luigi Pescarmona,

as eleições de 1948 , que foram decisivas para a Itália, porque havia a possibilidade do comunismo entrar pela ideia, por eleição na Itália. E não entrou por acaso. Então o comunismo ficou por quarenta anos numa oposição legal, firme, mas sem revolução numa atuação mesmo partidária. Estavam numa oposição democrática. Mas em 1948, os comunistas estavam na hora de ganhar, mas erraram no modo de fazer a propaganda, a publicidade. Salientaram muito o eliminaremos: eliminaremos a Igreja, eliminaremos não sei o quê. Então não calcularam a base católica histórica da Itália, que (...) Antonio Gramsci dizia: Na Itália o comunismo tem que tomar conta, tem que calcular que a base é católica. Se tivessem observado essa parte e eliminado as críticas à religião, à Igreja (...) Porque qualquer italiano como comunista manda os filhos estudar em escolas católicas (...) Foi nesse clima de efervescência política, no ano de 1948, quando eu ainda era criança, que ficava circulando pelas ruas e presenciando as manifestações políticas na minha cidade.

É importante ressaltar que as disputas entre os comunistas e os fascistas foram tão acentuadas nos anos anteriores à II GM quanto nos posteriores ${ }^{6}$. Um aspecto significativo para a constituição da trajetória de vida do Padre Pescarmona foram as socializações primárias e as secundárias firmadas ou tangenciadas em campos políticos sinalizados pela esquerda. Essa condição permite-nos referenciar, a partir de Fentress e Wickham (1992), que a memória é sempre social, pois os homens não são autômatos, mas relativamente autônomos diante das instituições sociais. Por outro lado, é necessário considerar uma dimensão da memória cuja expressão também se delimite pela herança dos acontecimentos marcantes da classe no núcleo familiar (CONNERTON, 1994). Inicialmente, a casa junto com o pai, um socialista;

\footnotetext{
${ }^{6}$ No ano de 1969, a Itália vivenciou o chamado "Outono quente", em virtude de greves e ocupações de fábricas pelos membros dos Conselhos de Fábrica. Em meio às tensões com os setores políticos conservadores, os neofascistas e os serviços secretos italianos e dos EUA, ocorreu uma violenta repressão, que acentuou o ânimo de setores comunistas que ingressaram nas Brigadas Vermelhas e no Poder Operário com práticas de política armada até o começo da década de 1970. Cf. MODONESI, 2010.
} 


\section{Revista Brasileira de História \& Ciências Sociais - RBHCS}

Vol. $8 \mathrm{~N}^{\mathrm{o}}$ 16, Julho - Dezembro de 2016

na sequência, as experiências em Minas Gerais durante a ditadura militar; e, por fim, os vínculos com os movimentos políticos dos camponeses na Paraíba. Embora esses vínculos tenham sido estabelecidos com os grupos de esquerda, havemos de perceber uma relação de equidistância, na medida em que o próprio Concílio do Vaticano II fazia críticas ao capitalismo no sentido de reformá-lo para garantir a dignidade entre os homens.

A Igreja, ciente do caráter universalista da religião, não quis se prender à dimensão de exclusividade para uma “classe", mas para o seu rebanho, sem fazer distinções. Esse foi o primeiro ponto que identificamos, no que se refere aos limites da TL entre os religiosos e no caso do Monsenhor Pescarmona, especificamente. Um dos fatores confirmadores dessa nossa análise foi a nova romanização realizada pelo Papa João Paulo II, cujo alvo foi a TL, o que implicou sanções contra alguns teólogos e a saída de outros de suas fileiras, como Leonardo Boff. Entre os leigos, esse fator resultou na formação de um movimento social com um maior quantum de autonomia, mesmo mantendo abertura para dialogar com a Confederação Nacional dos Bispos do Brasil (CNBB) e com a CPT. Estamos nos referindo ao Movimento dos Trabalhadores Rurais Sem Terra (MST).

O segundo eixo das nossas entrevistas foi o da formação contemporânea ao Vaticano II e sua vinda para o Brasil. Aqui nos defrontamos com alguns elementos sobre uma rígida formação em um seminário italiano, às expensas do pai e de um irmão. O monsenhor nos destacou a qualidade da formação proporcionada aos seminaristas, pois o seminário tinha professores de renomadas universidades europeias, como as de Budapeste, de Louvain ou de outras localizadas na Alemanha, conforme mostra este trecho da entrevista:

Eu entrei para o seminário com catorze anos. Pelos meus cálculos foi por volta de 1951-52 (...) Então eu quis continuar no seminário, que era pago, tal qual um colégio particular. Os estudos no seminário eram caros. Diziam-me às vezes: Você não vai pagar! (risos). Mas eu recebi ajuda, né? Recebi ajuda de papai, do meu irmão, logo depois de mim, que trabalhava muito para me ajudar a dar conta dos estudos, para pagar o seminário, os livros... No período em que estava no seminário me senti influenciado (...) com dois grandes representantes da democracia-cristã: a Itália, com De Gasper, e a Alemanha, com Adenauer. Os dois fundaram o Partido Democrata-Cristão (...) e conseguiram grande popularidade. Ambos eram remanescentes de grupos de resistência ao fascismo e ao nazismo. E os dois eram católicos fervorosos. 


\section{Revista Brasileira de História \& Ciências Sociais - RBHCS}

Vol. $8 \mathrm{~N}^{\circ}$ 16, Julho - Dezembro de 2016

Encontramos mais elementos para entender uma formação religiosa atenta às questões políticas do mundo inteiro. Mas a entrevista nos faz depreender que, mesmo tendo a influência paterna socialista, o campo religioso católico, representado pela democracia cristã, promoveu um grau de erosão em relação ao pensamento político de esquerda. Provavelmente, os traumas da II GM vivenciados pela sociedade europeia colaboraram para reflexões em instituições como a Igreja Católica, que sentiu a necessidade de um aggiornamento por meio de um novo concílio, o que pôde influir no curso da política por meio de um partido próprio: a Democracia Cristã, que, a rigor, distanciava-se de qualquer modalidade de experiência política socialista. Então, sempre é necessário, de acordo com a dinâmica da trajetória social de um indivíduo, ter a acuidade para se verificar o nível de tensão com a estrutura, ou, em outros termos, de um indivíduo com o campo. A relação entre determinado habitus e o campo em que o indivíduo se movimenta pode representar tanto a manutenção de uma dada estrutura social quanto sua reversão. Conforme a reflexão,

não se pode negar que há um estilo próprio a uma época, um habitus resultante de experiências comuns e reiteradas, assim como há um estilo próprio de um grupo. Mas para todo indivíduo existe também uma considerável margem de liberdade que se origina precisamente das incoerências e confins sociais e que suscita a mudança social (LEVI, 1996, p. 182).

Assim, destacamos que, mediante as condições sociais, o campo de possibilidades pode se apresentar com brechas, cuja mobilização de determinado grupo/classe social pode manifestar estratégias específicas quanto à ordem social. Em outro momento das entrevistas, o padre mencionou as reflexões sobre a história contemporânea durante o período de formação religiosa, como mostra este fragmento de uma entrevista que Luigi Pescarmona nos concedeu:

No nosso seminário, havia uma ligação muito grande com a história contemporânea. Recebíamos informações explícitas (...) sobre os diversos países: sobre a China, a Iugoslávia, a Rússia, a África, a América do Norte (...) Todo o movimento político ou de revolução ou de blocos (...) Nós sabíamos, líamos... Por exemplo, eu era um não-alinhado sobre pensamento, entre os blocos, do Muro de Berlim para lá e para cá! Eu era um não-alinhado! Eu acompanhava com atenção os países, que estavam emergindo, a exemplo da Iugoslávia, do Egito de Nasser, da Argélia de Ben Bella (...) Procurei manter vivo o meu senso crítico em todos os momentos. 


\section{Revista Brasileira de História \& Ciências Sociais - RBHCS}

Vol. $8 \mathrm{~N}^{\circ}$ 16, Julho - Dezembro de 2016

Ao que parece, a Igreja realizou, em alguns seminários, um trabalho preparatório para os novos desafios oriundos do pós-guerra, considerando a bipolaridade decorrente das tensões entre os EUA e a URSS e os seus aliados. Em uma escala de análise voltada para o contexto italiano, deve-se levar em conta a busca pela Igreja de garantir a autonomia diante do Estado italiano e das tentativas intervencionistas como as de Mussolini. Sobre os embates políticos na década de 1960 na Itália, o Padre Pescarmona rememorou:

E quando, em 1960, houve um governo filo-fascista, isto é, depois de anos e anos as pessoas voltavam a defender ideias fascistas. Eu me lembro que era um seminarista, perto já da batina, e fui para uma manifestação em Parma (...) para demonstrar o meu repúdio ao fascismo. Fui com um grupo de seminaristas para participar de uma manifestação (...) Havia tambores, tambores, que fazia muito barulho para demonstrar a indignação dos manifestantes contra as ideias da extrema-direita (...) Fui ordenado em setembro de 1961, em Alba. Lembrando que o Concílio de Vaticano II iniciou em 1962. E eu estreei no Brasil em 1966.

A vinda para o Brasil foi fruto de alguns contatos, no ano de 1965, com o bispo de uma Diocese recém-criada, a de Teófilo Otoni, em Minas Gerais, que estava participando do Concílio do Vaticano. A nova diocese necessitava de padres devido à dispersão da população. A Igreja realizava cursos preparatórios para os padres que vinham para a América Latina, conforme esta narrativa:

Informei-me e fique sabendo que havia um curso, em Roma, de preparação para América Latina, com quinze dias de atividades. E logo me inscrevi. Era em setembro-outubro. Fiz estudos sobre a América do Sul e o Brasil, também. Não me falaram nada do golpe de Estado. Estudamos mais os aspectos sociológicos e religiosos. Não falaram nada do político. Acho que não haviam ainda se dado conta ainda, pois estávamos em 1965 e o golpe havia ocorrido em 1964 (...) Ainda era inicial. E também a Igreja, com medo do comunismo, não percebeu onde havia caído. Então nos quinze dias, estudamos a sociologia das religiões do Brasil, as cidades. E eu, então em 1965, aceitei e fiz um contrato com o bispo, que me enviava na Itália, e com o bispo, que me recebia, e me aceitava em Minas Gerais.

Provavelmente, como os mestres da Igreja se encontravam em uma fase de transição, não se detiveram na discussão sobre os golpes de Estado na América Latina, buscando uma convivência dos religiosos com a ordem política, ou tenham acreditado que o terrorismo de Estado não fosse estimular a ativa participação de membros do clero com organizações de esquerda. O trabalho do padre, como 


\section{Revista Brasileira de História \& Ciências Sociais - RBHCS}

Vol. $8 \mathrm{~N}^{\circ}$ 16, Julho - Dezembro de 2016

certamente de tantos outros, foi feito no sentido de atender, mais imediatamente, às necessidades espirituais dos fiéis da paróquia, como foi rememorado:

Por isso, os primeiros anos foram só de adaptação, de conhecimento (...) Então, em 1969 não havia uma linha, havia uma abertura. Escutava, lia, participava de encontros. Mas depois de 69, em 70 eu estava decidido em participar em uma linha popular de mudança de governo. Havia uma necessidade premente de se constituir no Brasil um governo que verdadeiramente criasse oportunidades para todos. E também procurei me aproximar mais dos estudantes e dos trabalhadores. Nos anos $60 \mathrm{em}$ Minas Gerais, já havia feito a sua expulsão de pequenos produtores e sitiantes dos campos. E os campos estavam cheios de fazendas, quase que vazias de pessoal. A diferença é que no Nordeste a expulsão é posterior. Aqui os campos ainda estavam cheios de famílias. Lá em Minas muitos haviam partido para Rondônia, para o Maranhão, por conta do projeto do governo militar de Integrar para não entregar (...) E depois aquele projeto do governo tornou-se um fracasso.

A narrativa demonstra problemas sociais referentes aos trabalhadores desprovidos de terra e que se viram obrigados a migrar para outros estados ou a permanecer num processo de marginalização social nos subúrbios das cidades médias ou de grande porte. A indignação com as dificuldades oriundas do modelo econômico adotado pelos militares dava claros sinais, através das migrações, que resultavam na fragilização de comunidades e pelo fato de acentuar as condições de miséria e de pobreza, além de comprometer o próprio trabalho religioso. O fim da década de 1960 serviu como uma primeira experiência para se perceberem os problemas de ordem social no Brasil. Queremos salientar um ponto em relação à citação passada, quanto à pergunta feita sobre a participação política no Brasil: a referência à decisão de participar de uma linha popular de mudança de governo e a "necessidade premente de se constituir no Brasil um governo que verdadeiramente criasse oportunidades para todos”. Essa demanda esteve presente nas preocupações dos simpatizantes da TL, como uma forma alternativa de falar da "opção preferencial pelos pobres”. Assim, o religioso concluiu sua narrativa:

...porque nós iniciamos em 1967-68 ao ponto de sermos chamados de "padres de passeata", porque acompanhávamos os estudantes da UNE nas manifestações estudantis, que possuíam questões ideológicas boas (...) Não assustava se o bispo de Belo Horizonte torcia pelo Galo (Atlético Mineiro), mas se assustavam quando nós torcíamos pela UNE (risos). 


\section{Revista Brasileira de História \& Ciências Sociais - RBHCS}

Vol. $8 \mathrm{~N}^{\circ}$ 16, Julho - Dezembro de 2016

Setores da Igreja foram tocados pelas dificuldades enfrentadas pelos fiéis, dando vazão às práticas relacionadas à Doutrina Social da Igreja. O envolvimento do padre Luigi Pescarmona com camponeses vítimas da violência motivaram as ameaças de um proprietário rural da área de Teófilo Otoni, que resultou em sua transferência para outra diocese. Em uma entrevista realizada com um camponês sobre a violência contra o padre Luigi por um fazendeiro, em Minas Gerais, foi-nos narrado:

Eu entendia que o sindicato dos trabalhadores rurais não podia ser só um município e que teria que ser mais ampliado, porque aí é que a gente podia fazer o trabalho no município de Teófilo Otoni, no município de Ataléia, de onde ele também celebrou, o padre Luís celebrou, mas teve que vir correndo para não ser matado lá em Ataléia, (...) É poucos os fazendeiros que não tem pistoleiros contratados nas fazendas deles. E nessa história toda, o padre Luís falava a verdade, como fala até hoje, e um pistoleiro de latifúndio imprensou ele, que saiu correndo. E ele chegou em Teófilo Otoni (...) $\mathrm{Na}$ hora que ele saiu o padre pediu mais uma comunidade para celebrar missa e no mesmo dia ele foi celebrar fora de Teófilo Otoni. Eu fui encontra ele lá e ele estava desfigurado, quando eu encontrei ele lá (...) Ele foi lá não só para celebrar, mas para ver se o coração voltava a bater forte e aquela coisa toda, porque naquele momento ele estava fugido do latifúndio ${ }^{7}$.

Em seguida, deu curso à transferência para a Paraíba (1977), tocada pela violência, depois de alguns anos de aprendizagem da língua portuguesa, da necessidade de dissolver um grupo de padres italianos e dos caminhos a serem seguidos na via da TL. Sobre a chegada e a realização do trabalho junto com Dom Marcelo Carvalheira, em uma diocese marcada pela presença de padres estrangeiros (excetuando-se dois brasileiros: Joaquim, de Araruna, e Epitácio, da Serra da Raiz), recordou que a Igreja era mais sacramentalista em 1977. Porém a situação ganhou nova configuração quanto à questão agrária a partir de 1979, quando o monsenhor apresentou

a Dom Marcelo um mapa da Paraíba num isopor, marcando várias comunidades com alfinetes de cabeças coloridas: amarelo, verde, vermelho, negro e azul. Eram cinco níveis, que marcavam visualmente a situação da paróquia da catedral de Guarabira, junto com Araçagi, Pilõezinhos, Cuitegi, Alagoinha. Então, apresentei dentro de dois anos, 79 e 8o, esse mapa visual, que havia o nome do lugar, o alfinete e a legenda, que trazia um diagnóstico da situação. Suponhamos: comunidade onde só havia terço, novena, festa de padroeiro; comunidades que, além disso, se reunia para discutir os problemas locais; comunidades onde havia discussão e

\footnotetext{
7 Sílvio Rodrigues. Entrevista ao autor.
} 


\section{Revista Brasileira de História \& Ciências Sociais - RBHCS}

Vol. $8 \mathrm{~N}^{\mathrm{O}}$ 16, Julho - Dezembro de 2016

enfrentamentos de problemas e exigências, com reuniões e mobilizações; e, por fim comunidades que são abertamente envolvidas com a questão trabalhista, agrária ou a questão da mulher, que eram pontuadas com uma cor mais forte, o vermelho, né? Então essas cores demonstravam que uma dada comunidade estava ligada a um ou a outro aspecto.

Alguns padres (sobretudo, Cristiano e Leonardo) se empenharam em adquirir experiências no projeto de uma Igreja mais voltada para os problemas dos pobres rurais e urbanos. O Monsenhor Pescarmona dedicou-se, prioritariamente, às questões referentes à organização dos trabalhadores rurais, que denominou de imagem de um tripé: a organização das comunidades, a constituição de chapas para eleições dos sindicatos de trabalhadores rurais isentas da cooptação dos proprietários rurais e as discussões iniciais sobre um partido ainda novo, o Partido dos Trabalhadores (PT).

A partir de então, várias foram as “estratégias de subversão”, no sentido bourdieusiano (LOYOLA, 2002), adotadas para mitigar as condições de miséria rural, que passaram por obras em algumas comunidades, como pequenos açudes; resistência às expulsões de camponeses das terras de trabalho (após a morte do proprietário e da partilha entre os herdeiros, ou das dispensas do trabalho depois da limpeza dos terrenos para o plantio de capim, no caso da expansão da atividade criatória, ou da cana, que atendia ao setor sucroalcooleiro); coordenação de "entradas" (no sentido de ocupar as terras), em áreas de onde os camponeses haviam sido expulsos; apoio às mobilizações de trabalhadores urbanos, que não tinham um salário digno; romarias da terra; acampamento de camponeses em praças públicas de João Pessoa, com o objetivo de denunciar a lentidão dos processos de reforma agrária; manifestações em quartéis ou delegacias para denunciar as prisões arbitrárias de camponeses ou de membros da CPT; realização de programas de rádio, com o objetivo de fazer uma leitura da Bíblia, sob a ótica da TL; e, por fim, publicação de livros de cânticos com as músicas cantadas pelos camponeses, visando popularizálas para que fossem também cantadas nas missas.

A partir das narrativas do monsenhor, pudemos verificar que o trabalho na CPT e com os camponeses se estendeu do final da década de 1970 até os anos da década de 1990. Sua militância ao lado dos camponeses resultou em tentativas de atentados contra sua vida, além de ameaças de morte, processos com o fim de conter o trabalho com os camponeses, acusações de estar organizando movimentos com táticas de 


\section{Revista Brasileira de História \& Ciências Sociais - RBHCS}

Vol. $8 \mathrm{~N}^{\circ}$ 16, Julho - Dezembro de 2016

guerrilha; além de violências simbólicas ${ }^{8}$. Em alguns processos, verificamos algumas situações da debilidade entre as denúncias dos proprietários na justiça, devido a falta do cumprimento dos prazos ou da fragilidade das provas, que sendo forjadas poderiam ser refutadas por testemunhas e provas. No processo de no. 1173/87, decorrente da “invasão" da Fazenda Riacho e São Domingos em 30 de agosto de 1987, encontramos a denúncia da promotora Iolanda Dore do município de Bananeiras ao juiz Antônio Gomes em 30 de abril de 1988, contra o líder da “invasão” o padre Luigi Pescarmona, seguido por um grupo de camponeses (Chiquinho, Nequinho, Lula Fontes, Bier, Antônio Ferino) e de duas estrangeiras (Margherita Peisimo, italiana, e uma holandesa, não identificada pelos denunciantes. Foram feitas acusações de os "invasores" portarem armas escondidas em sacolas, a partir das denúncias de agentes do Estado, policiais, e funcionários da fazenda. A denúncia foi acatada pelo juiz, que expediu um mandato por entender o risco ao proprietário de ter nos seus domínios, pessoas com sacolas com objetos ocultos O processo terminou contrariando os interesses dos proprietários considerando a sentença do processo de no. 1173/87 foi a de extinção da punibilidade, pois o "crime" foi cometido em 30-08-1987, sendo apresentada a denúncia em 03-05-1988, e o prazo prescricional era 03-05-1990. Outro processo, que analisamos foi o de no. 1184/88, objeto da pela promotora Iolanda Dore Marques (Bananeiras), em 22 de fevereiro de 1988 ao juiz Antonio Gomes de Oliveira contra o padre Luigi Pescarmona e Francisco Gomes (Chiquinho), camponês militante na CPT. A acusação foi de que os denunciados haverem armado uma emboscada contra o filho do prefeito (que era o maior proprietário de terras do município de Dona Inês) e dois dos seus capangas afeitos à pistolagem: Luiz Moreira, vulgo “Carneiro”, capanga violento, associado à pistolagem e acusado por vários crimes) e Sebastião Mateus, que se deslocavam na estrada de Dona Inês para

\footnotetext{
8 Para Bourdieu (1996, p. 171), "A violência simbólica é essa violência que extorque submissões que sequer são percebidas como tais, apoiando-se em 'expectativas coletivas', em crenças socialmente inculcadas. Como a teoria da magia, a teoria da violência simbólica apoiando-se (...) em uma teoria da produção da crença, do trabalho de socialização necessário para produzir agentes dotados de esquemas de percepção e de avaliação que lhes farão perceber as injunções inscritas em uma situação, ou em um discurso, e obedecê-las". A violência simbólica assume o aspecto de uma "persuasão clandestina", sendo implacável por fazer parte da "ordem das coisas" servindo como esteio à dominação e à política (BOURDIEU, WACQUANT, 1995, p. 120). O Padre Luigi narrou-nos o uso de adjetivações por setores relacionados às classes dominantes agrárias (e conseguimos também atestar em processos e jornais), com o intuito de comprometer, diante da sociedade civil, o trabalho realizado com os camponeses: "padreco filho da puta" (por querer tomar "as terras dos outros"), "padre comunista" (porque "fazia política"), "terrorista" e "palestino" (pois andava com camponeses "armados" com foices e facões) e que "tinha um caso com uma jovem advogada" (como forma de desacreditá-lo diante dos fiéis, em virtude de um questionamento moral).
} 


\section{Revista Brasileira de História \& Ciências Sociais - RBHCS}

Vol. $8 \mathrm{~N}^{\circ}$ 16, Julho - Dezembro de 2016

Bananeiras, no dia 12 de dezembro de 1987. Apesar da denúncia a extinção do processo mais uma vez ocorreu, pois o "crime" havia sido cometido no dia 12-12-97, sendo a denúncia apresentada em 7-3-1988 e tendo prescrição em 7-3-1990. Porém, os denunciantes teriam que demonstrar várias incongruências, considerando o número de pessoas na cena do crime, porque o padre e o camponês foram caçados pelo filho do prefeito e pelos capangas. A experiência desses processos gerou entre os proprietários a necessidade de uma articulação política mais vigorosa, atentando para os prazos e fundamentando melhor as denúncias, que convergiu para tentativa de expulsão do padre. O monsenhor respondeu vários processos na Justiça, inclusive um de expulsão baseado na extinta Lei de Segurança Nacional, que virou jurisprudência no final da década do ano de 1990.

A disposição dos proprietários para praticar violências resultou na morte de um participante de uma Romaria da Terra e da presidente do Sindicato de Trabalhadores Rurais de Alagoa Grande (1983); torturas de camponeses; tiros de carabinas de calibre 12 contra mulheres e crianças (Dona Inês e Campo de Santana); prisões arbitrárias; violências que resultaram em abortos em áreas em que camponeses sofreram processos de despejos; necessidade de cirurgias reparadoras em crianças após a desocupação de áreas; destruições de casas e de plantios, entre outras.

Contudo, apesar das situações de violência física ou simbólica, as classes dominantes agrárias9, no Agreste e no Brejo paraibanos, criaram estratégias para conservar seus patrimônios, por meio de manobras jurídicas, do uso da imprensa ou mesmo de uma opção católica antissocialista, através de menções a um modelo de Igreja e de religiosos afeitos unicamente aos ritos ou, quando vinculados à política, à política dos proprietários de terra ou dos grupos conservadores. Um exemplo clássico foi o de Frei Damião, que, em suas pregações pelo Nordeste com sua prática missionária, combatia todas as formas de socialismo e, com alguma frequência,

\footnotetext{
9 Referimo-nos aqui às frações dos proprietários de terra assentados historicamente em latifúndios, que remontam ao Século XIX, com atividades produtivas consorciadas pela produção de cana-deaçúcar e/ou pecuária, mesmo durante a fase de modernização agrícola com o PROALCOOL. Manifestaram-se como classe no campo político, em momentos como os processos eleitorais, na contenção das Ligas Camponesas (década de 1960), no combate às ações da Pastoral da Terra, nas décadas de 1980 e 1990, usando artifícios junto ao Judiciário (local e nacional) e da imprensa como forma de reproduzir o poder político. Ver: (PAIVA NETO, 2011). Para uma leitura sobre a classe dominante agrária, ver: (MENDONÇA, 2006).
} 


\section{Revista Brasileira de História \& Ciências Sociais - RBHCS}

Vol. $8 \mathrm{~N}^{\mathrm{o}}$ 16, Julho - Dezembro de 2016

aparecia em palanques em campanhas eleitorais ${ }^{10}$ de políticos associados aos proprietários de terras ou às oligarquias regionais, como no caso de Fernando Collor de Mello.

Em contrapartida, a organização da CPT e dos camponeses resultou em cerca de 48 assentamentos na área da Diocese de Guarabira. A partir da luta pela terra, com a concretização da reforma agrária, coube à CPT captar recursos nas entidades estrangeiras e fazer a mediação com o Estado, com o objetivo de facilitar e garantir o êxito de outra fase na construção e na consolidação dos assentamentos, a chamada "luta na terra", para dar viabilidade a um projeto de reforma da sociedade, em um tempo de tantos impactos sobre os camponeses, em decorrência da mundialização e do agronegócio.

\section{Conclusão:}

A nossa intenção neste artigo foi analisar alguns aspectos da prática religiosa e política de um padre estrangeiro, que experienciou apenas um ano da sua condição de profissional do sagrado em uma cidade italiana, Sommariva (Perno), área de memórias de militantes resistentes ao fascismo na II Guerra Mundial e depois dela. O nosso objetivo foi analisar a constituição de um habitus pelo padre Luigi Pescarmona relacionado à condição de classe e um cristianismo pautado por aproximações à cultura política dos trabalhadores, germinando na Itália e aflorando no Brasil.

As condições históricas para esta essa experiência religiosa-política deram-se primeiramente em Minas Gerais, porém sem a intensidade dos conflitos ocorridos na Paraíba, sob a criteriosa orientação pastoral de Dom Marcelo Carvalheira, que fora secretário de Frei Betto, durante o episódio envolvendo os Dominicanos e Carlos Marighella. O apoio dado por bispos como D. Helder Câmara, Dom Aloísio Lorscheider e Dom José Maria Pires foi fundamental para Dom Marcelo coordenar uma diocese marcada por uma severa exclusão social e por cotidianas práticas de

\footnotetext{
10 Sobre essa questão, ver: CRUZ, João Everton da. Frei Damião: a figura do conselheiro no Catolicismo Popular do nordeste brasileiro. Belo Horizonte: Dissertação de Mestrado em Ciências da Religião/Pontifícia Universidade Católica de Minas Gerais, 2010, p. 11-12.
} 


\section{Revista Brasileira de História \& Ciências Sociais - RBHCS}

Vol. $8 \mathrm{~N}^{\mathrm{o}}$ 16, Julho - Dezembro de 2016

exploração social aos trabalhadores. E um dos colaboradores mais ativos no trabalho religioso-político junto aos camponeses foi o do padre Luigi Pescarmona, através da formação de militantes leigos pela CPT.

As áreas de conflito foram as mais diversas em uma fase de intensa participação de tantos leigos, apoiando as ocupações e auxiliando os religiosos na constituição de um catolicismo reconfigurado, ou seja, não mais o do Frei Damião, auxiliador da manutenção das desigualdades sociais, mas o da TL, envolvido com as causas de trabalhadores rurais expulsos das áreas, onde as famílias trabalhavam há décadas. Além disso, a falta do cumprimento dos direitos sociais como a carteira assinada também motivou a organização de trabalhadores e o apoio jurídico no Centro de Orientação aos Direitos Humanos em Guarabira.

$\mathrm{Na}$ pesquisa, nomeamos de habitus partisão as práticas do padre Luigi Pescarmona em um contexto símile a um jogo, entre agentes religiosos (no seu campo específico) e leigos em meio à luta de classes entre proprietários e camponeses. Porém, vale lembrar para finalizar, que essas experiências da TL foram entrando em crise na Paraíba, a partir da década de 1990, considerando o fato da guinada do Vaticano ao neoconservadorismo ainda no papado de João Paulo II. E assim, o campo religioso católico voltou a ser reconfigurado com a saída de João Paulo e a ascensão de Bento XVI (2005-2013). Na contramão do pontificado de João Paulo II (1978-2005), caracterizado pelo combate à TL, Dom Marcelo Carvalheira nas décadas de 1980 e 1990 deu apoio aos religiosos imbuídos pelas Doutrinas Sociais da Igreja ligadas ao fundamento de uma Igreja “preferencial aos pobres”. A partir daí, a CPT foi ganhando um papel menor na Diocese de Guarabira, porque foi a fase do advento de bispos politicamente conservadores, cabendo a Igreja o papel meramente relacionado aos assuntos devocionais alheios aos conflitos sociais. E essa tem sido a tendência no âmbito nacional.

\section{Referências bibliográficas:}

BETTO, Frei. Batismo de sangue. Rio de Janeiro: 6.ed., Civilização Brasileira, 1983 . 
BOURDÉ, Guy e MARTIN, Hervé. As escolas históricas. Mira-Sintra; Mem Martins: Publicações Europa-América, 1983.

BOURDIEU, Pierre e WACQUANT, Löic. Respuestas: por una Antropología reflexiva. México (DF): Ed. Grijalbo, 1995.

BOURDIEU, Pierre. Esboço da teoria e da prática. In: ORTIZ, Renato (org.). Pierre Bourdieu - Sociologia. Trad. Paula Monteiro. São Paulo: 2.ed., Ática, 1994, p. 4681.

BOURDIEU, Pierre. Razões práticas. Campinas: Papirus, 1996.

CAMPO, German Guzman. Camilo, el cura guerrillero. Bogotá: Servicios Especiales de Prensa, 1967.

CONNERTON, Paul. Como as sociedades recordam. Lisboa: Celta, 1993.

CRUZ, João Everton da. Frei Damião: a figura do conselheiro no Catolicismo Popular do nordeste brasileiro. Belo Horizonte: Dissertação de Mestrado em Ciências da Religião/Pontifícia Universidade Católica de Minas Gerais, 2010, p. 11-12.

FENTRESS, James e WICKHAM, Chris. Memória social. Lisboa: Teorema, 1992.

FORTES, Carolina Fortes. A produção literária dominicana no Século XII: uma breve visão sobre a hagiografia. In: COSTA, Sandro da, SILVA, Andréia C. L. F. da e SILVA, Leila R. (orgs.). Atas do Ciclo: a tradição monástica e o franciscanismo. Rio de Janeiro: UFRJ/IFCS, 2003.

GRASSI, Luigi Maria. La tortura di Alba e dell'albense (1944-1945). Alba: San Paolo, 3.ed., 1994.

GRIBAUDI, Maurizio. Escala, pertinência, configuração. In: REVEL, Jacques (org.). Jogos de escala. Rio de Janeiro: Editora FVG, 1998, p. 121-150.

HOBSBAWM, Eric. Era dos extremos: o breve Século XX. São Paulo: Companhia das Letras, 1995 .

LE BRETON, Binka. A dádiva maior: a vida e a morte corajosas da irmã Dorothy Stang. Editora Globo, 2008.

LE BRETON, Binka. Todos sabiam: a morte anunciada de Padre Josimo. Edições Loyola, 2000.

LE GOFF, Jacques. São Francisco de Assis. Rio de Janeiro: Record, 2001.

LE GOFF, Jacques. São Luís. Rio de Janeiro: Record, 2002.

LEVI, Giovanni. A herança imaterial: trajetória de um exorcista no Piemonte do Século XVII. Tradução: Cynthia M. de Oliveira. Rio de Janeiro: Civilização Brasileira, 2000.

LEVI, Giovanni. Usos da biografia. In: FERREIRA, Marieta Moraes e AMADO, Janaína. Usos e abusos da história oral. Rio de Janeiro: Editora da FGV, 1996.

LOYOLA, Maria Andréa. Pierre Bourdieu: entrevistado por Maria A. Loyola. Rio de Janeiro: Eduerj, 2002.

LUPO, Salvatore. Il fascismo: la politica in um regime totalitario. Roma: Donzelli Editore, 2005.

MAESTRI, Mário e CANDREVA, L. Antonio Gramsci. São Paulo: Expressão Popular, 2001. 
MAINWARING, Scott. A Igreja Católica e a política no Brasil (1916-1985). São Paulo: Brasiliense, 1989.

MENDONÇA, Sônia Regina de. A classe dominante agrária: natureza e comportamento (1964-1990). São Paulo: Expressão Popular, 2006.

MENEZES, Marilda Aparecida de. Redes e enredos nas trilhas dos migrantes. Rio de Janeiro: Relume Dumará; João Pessoa: EDUFPB, 2002.

MODONESI, Massimo. Subalternidade, antagonismo, autonomia. Buenos Aires: Consejo Latinoamericano de Ciencias Sociales - CLACSO; Prometeo Libros, 2010.

MORADIELLOS, Enrique. Las caras de Clío. Madri: Siglo XXI Editores, 2001.

MURPHY, Roseanne. Mártir da Amazônia: a vida de Dorothy Stang. São Paulo: Paulus, 2008.

PAIVA NETO, Francisco Fagundes. A Ação Católica: a resistência piemontesa ao fascismo (1933-1944). Histórica - Revista Eletrônica do Arquivo Público do Estado de São Paulo, $n^{0}$ 58, maio 2013.

PAIVA NETO, Francisco Fagundes. A trajetória religiosa-política do padre Luigi Pescarmona (1960-200o): entre o habitus partisão e o assistencial. Campina Grande: Tese de Doutorado em Ciências Sociais/Universidade Federal de Campina Grande, 2012.

PAIVA NETO, Francisco Fagundes. Reforma agrária e justiça. Anais do $35^{\circ}$. Encontro anual da ANPOCS, 2011. (Disponível em: <http://www.anpocs.org/portal/index.php?option=com docman\&task=cat_view\&gi $\mathrm{d}=181$ \&limit $=$ 20\&limitstart $=$ o\&order $=$ hits\&dir $=$ ASC\&Itemid $=280>. \quad$ Acesso $\mathrm{em}$ 03/09/2015).

PEREIRA, Nilo. Dom Vital e a questão religiosa no Brasil. Recife: Imprensa Universitária/UFPE, 1996.

REVEL, Jacques. A história ao rés-do-chão. In: LEVI, Giovanni. A herança imaterial. Rio de Janeiro: Civilização Brasileira, 2000, p. 7-37.

SALTALAMACCHIA, HOMerO. La historia de vida: reflexiones a partir de una experiencia de investigación. Puerto Rico: Ediciones SIJUP, 1992.

SANTANA, Manoel Henrique de Melo. Padre Cícero do Juazeiro: condenação e exclusão eclesial à reabilitação histórica. Maceió: EDUFAL, 2009.

SASSOON, Donald. Mussolini e a ascensão do fascismo. Tradução Clóvis Marques. Rio de Janeiro: Agir, 2009.

SILVA, Claudia Neves da. Igreja católica, assistência social e caridade: aproximações e divergências. Sociologias, Porto Alegre, ano 8, $\mathrm{n}^{0}$ 15, p. 326-351, jan/jun. 2006.

SILVEIRA, Ildefonso e REIS, Orlando dos (orgs.). São Francisco de Assis: escritos e biografias de São Francisco de Assis. Petrópolis: Vozes, 2000.

SOBREIRA, Azarias. O Patriarca de Juazeiro. Petrópolis: 1968.

\section{Entrevistas:}


Revista Brasileira de História \& Ciências Sociais - RBHCS

Vol. $8 \mathrm{~N}^{\mathrm{o}}$ 16, Julho - Dezembro de 2016

Monsenhor Luigi Pescarmona, coordenador da CPT/Guarabira. Entrevistas concedidas ao autor entre 2008 e 2010.

Sílvio Rodrigues, ex-sindicalista. Entrevista concedida ao autor em Montes ClarosMG, 19 de maio de 2010.

\section{Processos-crime}

PROCESSO no. 1173/87, Comarca de Bananeiras/PB, Réu: Luigi Alberto Pescarmona e outros. Ação cautelar incidental de atentado.

PROCESSO no. 1184/88, Comarca de Bananeiras/PB. Réu: Luigi Alberto Pescarmona e outros. Ação cautelar incidental de atentado

Recebido em Setembro de 2015

Aprovado em Setembro de 2016 